\title{
Adoção de práticas colaborativas: fatores inibidores na cadeia de suprimentos de FLV
}

\author{
Angela Cristina Marquil \\ Rosane lucia Chicarelli Alcantarall
}

\section{INTRODUÇÃO}

A gestão da cadeia de suprimentos tem se caracterizado pela introdução de várias práticas de apoio à gestão dos diferentes processos de negócios existentes ao longo da cadeia, como, Vendor Managed Inventory (VMI), Continuous Replenishment Program (CRP), Efficient Consumer Response (ECR) e Collaborative Planning, Forecasting and Replenishment (CPFR) (PIRES, 2004; VIVALDINI; PIRES, 2010). As indústrias produtoras dos itens de mercearia básica fornecem para as grandes redes varejistas e os próprios varejistas fazem uso de tais práticas com os objetivos de melhor atender aos requisitos da demanda e reduzir os custos dos processos ao longo da cadeia de suprimentos. Garantir a disponibilidade do produto no ponto de venda é um desafio para os varejistas (GRANT; FERNIE, 2008; AASTRUP; KOTZAB, 2009) além de ser um dos componentes-chave do nível de serviço ao cliente no varejo (AASTRUP; KOTZAB, 2010).

No entanto, ao se pesquisar a gestão da cadeia de suprimentos de categorias mais específicas, como a de hortifrúti, pode-se constatar que há significativas diferenças nessa cadeia em comparação à cadeia de produtos industrializados/processados, onde se incluem os itens de mercearia seca. As diferenças são decorrentes, entre outros fatores, de particularidades do mercado fornecedor, das condições de concorrência, e do papel estratégico dos itens de hortifrúti para o varejo supermercadista.

Com relação ao mercado fornecedor, a ausência da indústria como elo intermediário entre o varejo supermercadista e os fornecedores de matéria-prima faz que essa categoria de produtos tenha características únicas de suprimento. No caso de produtos industrializados, conforme já mencionado, a gestão da cadeia de suprimentos tem se caracterizado pela introdução de várias práticas de apoio à gestão dos processos de negócios, o que não é observado na gestão da cadeia de suprimentos dos itens de hortifrúti. Segundo pesquisa realizada por Lourenzani e Silva (2004) no setor de hortaliças, a baixa eficiência na distribuição é considerada um dos maiores entraves para o bom desempenho competitivo de toda a cadeia.

Adicionalmente, as condições de concorrência desse setor também diferem das condições do setor de itens industrializados. No caso dos itens de mercearia seca, por menor que seja a empresa, comparada com gigantes como Unilever e Procter \& Gamble, esses produtos competem entre si dentro dos variados nichos de mercado. Em contrapartida, no caso dos itens de hortifrúti, por se tratar de commodities, frequentemente comercializados a granel, a

Operation \& Information Management Group Aston Business School. Aston University.

II Departamento de Engenharia de Producao. Universidade Federal de São Carlos. 
concorrência se dá entre os canais de distribuição. As redes varejistas competem com o varejo independente, feiras livres, distribuidores autônomos de produtos orgânicos e varejões que, muitas vezes, apresentam produtos com maior frescor e a um preço menor.

Soma-se à característica de fornecimento e às condições de concorrência o atual crescimento da importância estratégica do setor de hortifrúti para as redes varejistas. Segundo Pelição, Neves e Martinelli (1999), o varejo supermercadista tem aumentado a área de vendas dedicada aos produtos de hortifrúti, visando oferecer tudo "sob um mesmo teto" ao consumidor. Do ponto de vista do supermercado, um setor de hortifrúti bem abastecido pode ser responsável pelo aumento no fluxo de pessoas na loja e também pelo aumento do ticket médio. Isso porque a perecibilidade desses itens faz que o consumidor necessite ir ao ponto de venda com maior frequência, o que poderá resultar na compra de outros produtos.

Nesse contexto, este artigo tem por objetivo identificar os fatores que inibem a adoção de práticas de gestão colaborativa, especificamente VMI, CRP, ECR e CPFR, no elo fornecedor-varejo supermercadista na cadeia de suprimento de frutas e legumes.

\section{RefERENCIAL TEÓRICO}

\section{Colaboração na cadeia de suprimentos}

No contexto da gestão da cadeia de suprimentos, a colaboração pode ser interpretada como duas ou mais organizações independentes trabalhando de maneira conjunta para alinhar seus processos produtivos, bem como, criar valor para os consumidores finais e demais stakeholders, alcançando um sucesso maior do que se elas atuassem de forma livre (SIMATUPANG; WRIGHT; SRIDHARAN, 2004).

Cabe destacar, entretanto, que o relacionamento colaborativo não deve ser adotado entre a organização e todos os agentes com os quais ela interage. Idealmente, escolhe-se aqueles diretamente relacionados ao objetivo chave da organização em questão (BARRATTT, 2004). Desse modo, pode haver diferença no grau de colaboração entre agentes de uma mesma cadeia, devido à estrutura das empresas que constituem essa cadeia, ao interesse que o fornecedor possui em relação ao distribuidor e, por fim, às ações realizadas pelos parceiros e pelas pessoas responsáveis pela relação (PIGATTOO; ALCANTARA, 2007).

\section{PrÁtICAS de APOIO À GESTÃO NA CADEIA DE SUPRIMENTOS}

Diversas pesquisas investigam a implantação de práticas de gestão colaborativas como VMI, CRP, ECR e CPFR no varejo como formas de viabilizar a colaboração e o compartilhamento de informações (IRELAND; BRUCE, 2000; KURNIA; JOHNSTON, 2000; 2001; BARRATT, 2003; 2004; WHIPPLE; RUSSEL. 2007). Entre as práticas de gestão colaborativas mais comumente implementadas por empresas varejistas estão os sistemas que envolvem o processo de reposição automática.

Para Sabath, Autry e Daugherty (2001), programas em que a reposição de estoques é disparada pelas vendas atuais ao invés de previsões de demanda de longo prazo e estoques de segurança, são chamados de sistemas de reposição automática (Automatic Replenishment Programs - ARPs). Esses sistemas de reposição de inventário foram rotulados de várias maneiras, como VMI, Quick Response (QR), CRP e ECR (DAUGHTERTY; MYERS; AUTRY, 1999; SABATH; AUTRY; 
DAUGHERTY, 2001). Entre os ARPs, QR não foi identificado como uma prática utilizada pelo varejo supermercadista, pois, segundo Daughterty, Myers e Autry (1999), é um ARP tipicamente implementado na indústria de vestuário e, portanto, não será estudado neste artigo.

\section{- VMI}

VMI é uma prática na qual o fabricante (ou o fornecedor) tem a responsabilidade de gerenciar a política de inventário do cliente, incluindo o processo de reposição (VIVALDINI; PIRES, 2010). VMI somente pode funcionar se o relacionamento for uma parceria baseada na confiança, com extensiva troca de informação e seu funcionamento efetivo requer significativa integração de informações e de coordenação de processos e de operações entre as empresas envolvidas (PIRES, 2004; VIVALDINI; PIRES, 2010).

Um dos pontos fracos do VMI é a falta de visibilidade da cadeia de suprimentos como um todo (IRELAND, BRUCE, 2000). Segundo Barratt (2003), em geral, no VMI as políticas de inventário e processo de reposição são baseadas na variação dos níveis de estoques do depósito do cliente, ou centro de distribuição, o que resulta em falta de visibilidade dos dados do ponto de venda (PDV). Essa falta de visibilidade sobre dados de ponto de venda e estoques de fundo de loja é uma limitação do VMI. Cabe ressaltar que a limitação indicada por Barratt (2003) não necessariamente é decorrente do conceito do VMI, mas sim da forma como as empresas envolvidas aplicam o conceito, uma vez que existem empresas que utilizam os dados de PDV para disparar a reposição. Esse exemplo pode ser um indicador que a limitação não esteja na concepção do VMI como conceito, mas na sua implementação.

\section{- CRP}

O CRP evoluiu do VMI e trata de alguns dos seus pontos fracos. A implementação do CRP requer que 1) os membros da cadeia de suprimentos compartilhem mais informações/ dados; 2) utilize sistemas em comum para consistência dos dados e medição de desempenho, e 3) promova a tomada de decisão conjunta (BARRATT, 2003). Como parte da evolução do VMI, o CRP frequentemente requer que os fabricantes usem o sistema de reposição automático de propriedade do varejista (SABATH; AUTRY; DAUGHERTY, 2001).

Segundo Sabath, Autry e Daugherty (2001), um método para se classificar os ARPs é baseado no local onde a decisão de reposição é feita, por exemplo, pelo comprador ou pelo vendedor. Para os autores, a terminologia usada com maior frequência é CRP e VMI, sendo que nas duas práticas, a reposição é disparada por dados de venda. No entanto, a responsabilidade pela política de inventário e pelas decisões de reposição é diferente nas duas abordagens. No CRP, o comprador é responsável por essas decisões, enquanto no VMI, o vendedor assume maiores responsabilidades e de fato gerencia os níveis de inventário (SABATH; AUTRY; DAUGHERTY, 2001).

\section{- ECR}

O ECR visa um melhor atendimento das reais demandas dos clientes por meio de um sistema de reposição automática dos estoques consumidos nos PDVs (PIRES, 2004), ou seja, o ECR é outro ARP. A implementação do ECR quase sempre requer algum investimento adicional em tecnologias de informação, como em sistemas de código de barras, scanners, EDI - Eletronic Data Interchange, e RFID - Radio-Frequency IDentification (PIRES, 2004; VIVALDINI; PIRES, 2010). 
Segundo Barratt (2003), para implementar o ECR é necessário desenvolver um relacionamento baseado na confiança entre fabricantes e varejistas, elementos estes já considerados necessários na implementação do CRP e do VMI, com o compartilhamento de informações estratégicas de modo a otimizar os resultados da cadeia de suprimentos. No entanto, no ECR varejistas, distribuidores e fornecedores planejam suas operações de forma independente. Essa é uma importante lacuna do ECR (HOLMSTRÖM et al., 2002) que o CPFR busca preencher. Ressalta-se que, é importante refletir sobre o ERC como um bloco de construção para o CPFR, isso porque o ECR criou o alicerce para se construir o CPFR (WHIPPLE; RUSSELL, 2007).

\section{- CPFR}

O CPFR visa facilitar a colaboração entre empresas, principalmente no que diz respeito aos processos básicos de reposição de estoques, previsão de vendas e de planejamento do suprimento/produção. Significa grande vantagem em termos de integração, pois coloca os processos de planejamento/gestão da demanda sob uma única coordenação (PIRES, 2004; VIVALDINI, PIRES, 2010). O objetivo do CPFR é a colaboração de toda a cadeia de valor entre todos os parceiros de negociações que têm intersecção, ou algum efeito, no valor do produto para o consumidor final (IRELAND; BRUCE, 2000).

O CPFR tem elevado o nível das relações entre os parceiros comerciais, possibilitou a criação de valor e melhorou a competitividade no mercado. O lugar mais óbvio para se concentrar quando do desenvolvimento de atividades de colaboração foi o ponto onde o consumidor, o varejista e o fabricante convergem, ou seja, na intersecção da qual um produto foi planejado, o pedido foi colocado e o produto foi reposto. Segundo Ireland e Bruce (2000), é nesse ponto de intersecção que está a fonte de problemas, como excesso de estoque, falta de produto, as oscilações na produção, e é onde o CPFR age, como ferramenta de colaboração para a previsão de demanda e planejamento oferecendo uma oportunidade para os resultados positivos.

O Quadro 1 apresenta um comparativo das práticas de gestão colaborativas VMI, CRP, ECR e CPFR.

Quadro 1: Comparativo das práticas de gestão colaborativas VMI, CRP, ECR e CPFR.

\begin{tabular}{|c|c|c|}
\hline & $\begin{array}{r}\text { Objetivo Principal } \\
\end{array}$ & Informação Compartilhada \\
\hline$\sum$ & - Otimização do gerenciamento do estoque. & $\begin{array}{l}\text { - Níveis de estoque; } \\
\text { - Consumo de estoque. }\end{array}$ \\
\hline 金 & - Controle conjunto de ressuprimento. & $\begin{array}{l}\text { - Historico de consumo; } \\
\text { - } \quad \text { Previsão de vendas. }\end{array}$ \\
\hline$\underset{\bigcup}{\simeq}$ & $\begin{array}{l}\text { Melhor entendimento do comportamento do } \\
\text { mercado e redução dos custos de transação. }\end{array}$ & $\begin{array}{l}\text { - Consumo do estoque no PDV; } \\
\text { - Histórico de consumo; } \\
\text { - Comportamento do consumo; } \\
\text { - Ações de marketing. }\end{array}$ \\
\hline 产 & $\begin{array}{l}\text { Planejamento conjunto de previsão de vendas, } \\
\text { planos de ressuprimento e tratativa de exceções. }\end{array}$ & $\begin{array}{l}\text { - Previsão de demanda; } \\
\text { - } \quad \text { Planos de vendas; } \\
\text { - } \text { Metas; } \\
\text { - Análise conjunta de exceções.; } \\
\text { - Planejamento de marketing. }\end{array}$ \\
\hline
\end{tabular}

Fonte: Adaptado de Pellegrinotti, 2011, p. 26 


\section{ELEMENTOS NECESSÁRIOS PARA A IMPLEMENTAÇÃO DAS PRÁTICAS DE GESTÃO}

O Quadro 2 agrupa os principais elementos necessários para a implementação de cada uma das quatro práticas de gestão de apoio à gestão colaborativa, VMI, CRP, ECR e CPFR, oriundos da literatura e foco deste estudo.

O Quadro 3 apresenta a comparação dos requisitos identificados como necessários para a implementação de cada uma das práticas. A comparação confirma que para se implementar qualquer uma das práticas de apoio à gestão colaborativa abordadas neste artigo, é necessário, pelo menos, relacionamentos colaborativos baseados em confiança e extensa troca de informações, a qual, normalmente, é feita com o suporte da tecnologia de informação. Além disso, os elementos exibidos como necessários nos Quadros 2 e 3, podem ser considerados condições necessárias, porém, não se pode afirmar que sejam suficientes.

Quadro 2: Requisitos para a implementação de práticas de gestão colaborativa na cadeia de suprimentos.

\begin{tabular}{|c|c|c|}
\hline & Requisitos & Autor(es), ano \\
\hline$\sum$ & $\begin{array}{l}\text { - Relacionamento de parceria baseado na confiança } \\
\text { - Extensiva troca de informação } \\
\text { - Integração de informações } \\
\text { - } \text { Coordenação de processos e operações entre as empresas da cadeia } \\
\text { - Objetivos compartilhados/ mútuos } \\
\text { - Uso intensivo de tecnologias de informação e integração de sistemas }\end{array}$ & $\begin{array}{l}\text { (KURNIA; JOHNSTON, } \\
\text { 2001; PIRES, 2004; DONG; } \\
\text { XU DRESNER, 2007; } \\
\text { VIVALDINI; PIRES, 2010) }\end{array}$ \\
\hline 气ิ & $\begin{array}{l}\text { - Compartilhamento de informações e dados com os membros da } \\
\text { cadeia de suprimentos } \\
\text { - Uso de sistemas em comum para consistência dos dados e medição } \\
\text { de desempenho, } \\
\text { - Tomada de decisão conjunta } \\
\text { - Uso de tecnologia de informação e integração de sistemas }\end{array}$ & $\begin{array}{l}\text { (KURNIA; JOHNSTON, } \\
\text { 2001; BARRATT, 2003) }\end{array}$ \\
\hline 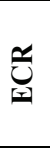 & $\begin{array}{l}\text { - Relacionamento baseado na confiança entre fabricantes e varejistas } \\
\text { - Compartilhamento de informações estratégicas } \\
\text { - Uso de tecnologia de informação e integração de sistemas }\end{array}$ & $\begin{array}{l}\text { (KURNIA; JOHNSTON, } \\
\text { 2001; BARRATT, 2003; } \\
\text { PIRES, 2004; VIVALDINI; } \\
\text { PIRES, 2010) }\end{array}$ \\
\hline Ũ & 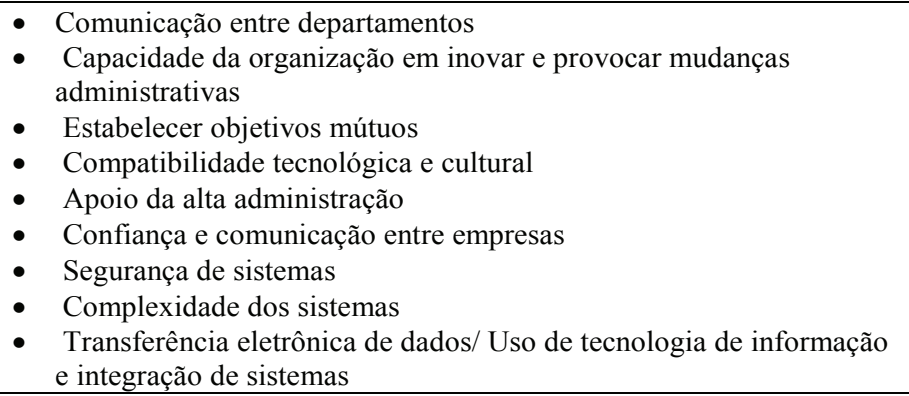 & $\begin{array}{l}\text { (KURNIA; JOHNSTON, } \\
2001 ; \text { FU et al., 2010) }\end{array}$ \\
\hline
\end{tabular}

Fonte: Elaborado pelas autoras 
Quadro 3: Comparação dos requisitos para a implementação das práticas de gestão colaborativa analisadas.

\begin{tabular}{|c|c|c|c|c|}
\hline Requisitos & VMI & CRP & ECR & CPFR \\
\hline Comunicação entre departamentos & & & & $\mathrm{X}$ \\
\hline $\begin{array}{l}\text { Capacidade da organização em inovar e provocar mudanças } \\
\text { administrativas }\end{array}$ & & & & $\mathrm{X}$ \\
\hline Apoio da alta administração & & & & $\mathrm{X}$ \\
\hline Relacionamento de parceria baseado na confiança & $\mathrm{X}$ & & $\mathrm{X}$ & $\mathrm{X}$ \\
\hline $\begin{array}{l}\text { Extensiva troca/ compartilhamento de informação com os } \\
\text { membros da cadeia de suprimentos }\end{array}$ & $\mathrm{X}$ & $\mathrm{X}$ & $\mathrm{X}$ & \\
\hline $\begin{array}{l}\text { Integração de informações/ Uso de sistemas em comum/ } \\
\text { Compatibilidade tecnológica }\end{array}$ & $\mathrm{X}$ & $X$ & & $\mathrm{X}$ \\
\hline $\begin{array}{l}\text { Coordenação de processos e operações entre as empresas da } \\
\text { cadeia de suprimentos }\end{array}$ & $\mathrm{X}$ & & & \\
\hline Objetivos compartilhados/ mútuos & $\mathrm{X}$ & & & $\mathrm{X}$ \\
\hline Tomada de decisão conjunta & & $\mathrm{X}$ & & \\
\hline Compatibilidade cultural & & & & $\mathrm{X}$ \\
\hline $\begin{array}{l}\text { Uso intensivo de tecnologias de informação e integração de } \\
\text { sistemas/ segurança de sistemas }\end{array}$ & $\mathrm{X}$ & $\mathrm{X}$ & $X$ & $X$ \\
\hline
\end{tabular}

Fonte: Elaborado pelas autoras

Cada um dos onze elementos apresentados no Quadro 3 desempenha um papel fundamental para o sucesso da implementação das práticas de apoio à gestão às quais eles se referem, conforme pode-se observar a seguir:

Comunicação entre departamentos - Fu et al. (2010) sugerem que uma das melhores formas de facilitar o CPFR é pela ênfase na integração entre departamentos, como marketing, finanças e compras no varejo;

Capacidade da organização em inovar e provocar mudanças administrativas - trabalhar a mudança, especialmente, em termos educacionais e comportamentais (PIRES, 2004);

Apoio da alta administração - Conforme apontado por Fawcett, Magnan e McCarter (2008), é importante que os gerentes atentem para a educação e treinamento do pessoal, procurando incorporar neles a predisposição para colaborar tanto no âmbito interno quanto externo à empresa. Além disso, Fawcett, Magnan e Fawcett (2010) recomendam um nível de interação entre os gerentes das organizações que compõem determinada cadeia de suprimentos;

Relacionamento de parceria baseado na confiança - O relacionamento baseado em confiança envolve parceiros compartilhando um conjunto comum de crenças, entendendo que os agentes envolvidos na transação, seja ela interna ou externa, desfrutam de credibilidade (VIEIRA; YOSHIZAKI; HO, 2009);

Extensiva troca/compartilhamento de informação com os membros da cadeia de suprimentos - de acordo com Simatupang e Sridharan (2002), os membros da cadeia compartilham informações, tanto a montante quanto a jusante, que fornecem adequada visibilidade entre as funções internas da empresa e entre as organizações envolvidas. Os autores expõem, ainda, que os dados mais comumente compartilhados são disponibilidade de recursos, desempenho atual, status dos processos de previsão de demanda, atendimento do pedido, entregas, reposição entre outros. Por fim, eles relatam que os avanços da tecnologia de informação, como internet, possibilitaram que tais dados pudessem ser coletados e transferidos em tempo real ou sob demanda; 
Integração de informações/Uso de sistemas em comum/Compatibilidade tecnológica - através de portais eletrônicos interligados que viabilizem o compartilhamento de informações, os membros da cadeia podem simplificar e agilizar não somente o fluxo de informações, como também o fluxo de produtos físicos (SHEU; YEN; CHAE, 2006);

Coordenação de processos e operações entre as empresas da cadeia de suprimentos - Cadilhon et al. (2005) dizem que, ao desenvolver um planejamento conjunto referente à produção, às previsões de demanda e à reposição de produtos, os membros da cadeia podem balancear seus processos produtivos de maneira mais apropriada. Com isso, reduzem a possibilidade de ocorrência de perdas, de manutenção de altos níveis de estoques e, ainda, de faltas de produtos disponíveis nas gôndolas para a aquisição por parte do consumidor final;

Objetivos Compartilhados/mútuos - Simatupang e Sridharan (2002) consideram que o ponto inicial da colaboração consiste na definição de objetivos e metas mútuos para os membros, de modo a sinalizar quais serão as vantagens e os desafios da colaboração que sejam claramente superiores ao status quo;

Tomada de decisão conjunta - quanto à tomada de decisão, Simatupang e Sridharan (2002) não tratam desse ponto em detalhe suficiente, apenas indicam que o escopo das decisões varia de acordo com o horizonte de tempo que se pretende que a colaboração perdure e, então, o escopo das decisões que seriam compartilhadas. Por exemplo, no curto prazo os autores sugerem que seja necessária intervenção em deliberações relacionadas à previsão de demanda, atendimento do pedido, transporte, reposição, promoção e preço. Exemplos de decisões de médio prazo consistem em segmentação de mercado, desenvolvimento de produto e capacitações logísticas. Já os objetivos de negócio e estratégias de marketing correspondem a decisões de longo prazo;

Compatibilidade cultural - entende-se que a cultura organizacional está associada ao modo que a organização procura estruturar-se, oferecendo condições para que o relacionamento colaborativo possa de fato ocorrer. Möller e Svahn (2004) explicam que indivíduos habituados a uma cultura de visão individualista são mais propensos à motivação e ao alcance de objetivos pessoais, por sua vez, aqueles acostumados com a cultura direcionada ao coletivismo tendem a trabalhar melhor com metas e recompensas relacionadas a equipes. Ou seja, para que duas empresas colaborem, é preciso que haja compatibilidade cultural entre elas;

Uso intensivo de tecnologias de informação e integração de sistemas/segurança de sistemas - de acordo com Pramatari (2007), a tecnologia de informação tem desempenhado um papel facilitador para a adoção de práticas colaborativas na gestão da cadeia de suprimentos. No que se refere à segurança de sistemas, observa-se que este é um elemento pouco discutido na literatura sobre gestão da cadeia de suprimentos. No entanto, Fu et al. (2010) identificaram a segurança de sistemas como um fator que afeta a implementação de práticas colaborativas com intensivo uso de tecnologia de informação, conforme pesquisa com especialistas familiarizados com a implementação de tais práticas no varejo. Segundo Turban, Rainer Jr. e Potter (2007), segurança de sistemas diz respeito à suscetibilidade dos dados e informações organizacionais, incluindo, por exemplo, a necessidade de se investir recursos na adoção de procedimentos, dispositivos ou softwares destinados a evitar o comprometimento do sistema. 


\section{MÉTODO DE PESQUISA}

A abordagem adotada para este trabalho foi qualitativa, sendo o estudo de caso a estratégia de investigação. "Os estudos de caso têm como foco situações holísticas em contextos da vida real, e tendem a ter um contexto de interesse delimitado, tais como uma organização, uma indústria em particular, ou um determinado tipo de operação" (ELLRAM, 1996, p. 99). Por sua vez, Eisenhardt (1989, p. 534) afirma que "o estudo de caso é uma estratégia de pesquisa que enfoca a compreensão da dinâmica dentro de um único contexto".

Dado o contexto do varejo supermercadista, este trabalho busca responder à seguinte questão: quais são os fatores que inibem a adoção de práticas de gestão colaborativa, especificamente VMI, CRP, ECR e CPFR, no elo fornecedor-varejo supermercadista na cadeia de suprimento de frutas e legumes? Esta pergunta de pesquisa e o objetivo nortearam a seleção do estudo de caso.

A empresa selecionada foi uma rede do varejo supermercadista, a qual será chamada de Empresa X, que ocupou, em 2010, uma das quatro primeiras posições do ranking de empresas do varejo supermercadista (RANKING ABRAS, 2011). Essa escolha fundamenta-se no fato de que a rede varejista selecionada, por ser uma das empresas líderes no setor e por adotar essas práticas com fornecedores de outras categorias, por exemplo, higiene e limpeza, é uma empresa do varejo supermercadista com maiores chances de conseguir implementar as práticas de apoio à gestão foco de estudo. Dessa forma, tem-se como objeto de estudo uma organização com processos estruturados, e representativo da situação mais próxima do ideal no contexto nacional da cadeia de frutas e legumes distribuídos para a comercialização in natura.

\section{RESULTADOS}

Com uma ampla rede de abastecimento, composta por centenas de lojas, entre supermercados e hipermercados, e diversos centros de distribuição que atendem às lojas em todo o Brasil, a Empresa $X$ teve faturamento acima de 15 bilhões de reais em 2010. A Empresa $X$ tem um centro de distribuição que concentra a distribuição de frutas e legumes para a maioria das lojas do Estado de São Paulo. Ao total, foram realizadas três visitas ao centro de distribuição, além de um total de dez entrevistas com funcionários da rede varejista e com um de seus fornecedores, conforme se observa no Quadro 4 na página seguinte.

$\mathrm{Na}$ Empresa $X$ existe uma diretriz, a qual estabelece que se deve priorizar a compra direta de produtores rurais de forma a comprar a menor quantidade possível de atacadistas e distribuidores. Para os itens de frutas e legumes, entre 70\% e 80\% dos fornecedores da Empresa $X$ são produtores rurais, e de $20 \%$ a $30 \%$ são atacadistas e distribuidores. Ao se analisar frutas e legumes separadamente, pode-se observar que há uma maior proporção de itens da categoria legumes que são fornecidos direto de produtores rurais do que a proporção de itens da categoria frutas, sendo que aproximadamente $80 \%$ dos itens da categoria de legumes são fornecidos direto do produtor rural e esse percentual não varia ao longo do ano. 
Quadro 4: Área e cargo dos entrevistados.

\begin{tabular}{llll}
\hline \multicolumn{1}{c}{ Área do Entrevistado } & \multicolumn{1}{c}{ Cargo dos entrevistados } & \multicolumn{1}{c}{$\begin{array}{c}\text { Número de } \\
\text { entrevistas }\end{array}$} \\
\hline Compras da Empresa $X$ & Comprador Sênior & 1 & 1 \\
\hline Centro de Distribuição de frutas e & Gerente do CD & 1 \\
\cline { 2 - 3 } legumes (CD) da Empresa $X$ & Chefe de operações do turno 1 & 1 \\
\cline { 2 - 3 } & Encarregado de recebimento do turno 1 & 1 \\
\cline { 2 - 3 } & Encarregado de recebimento do turno 2 & 1 \\
\cline { 2 - 3 } & Encarregado de separação do turno 2 & 1 \\
\cline { 2 - 3 } & Encarregado de Expedição do turno 1 & 1 \\
\cline { 2 - 3 } & Encarregado de Expedição do turno 3 & 1 \\
\cline { 2 - 3 } & Programador (PCP) & 1 (entrevista com mais \\
Fornecedor Y & $\begin{array}{l}\text { Proprietário da Empresa } \\
\text { Comprador }\end{array}$ & \\
\hline & Gerente Financeiro & \\
& Gerente de operações e logística & \\
& & \\
& & \\
& & & \\
& &
\end{tabular}

Fonte: Elaborado pelas autoras

Diferentemente da categoria de legumes, na categoria de frutas esse percentual pode variar ao longo do ano. Na época de safra, $80 \%$ dos itens da categoria de frutas são fornecidos direto do produtor rural e $20 \%$ dos itens são fornecidos por atacadistas e distribuidores. No entanto, nos períodos de entressafra, a proporção dos itens fornecidos direto do produtor rural diminui em até 10\% do volume total, dando mais espaço para mercadorias fornecidas por distribuidores e atacadistas.

\section{RELACIONAMENTO DO PONTO DE VISTA DA EMPRESA $X$}

A Empresa $X$ possui um cadastro obrigatório de todos os seus fornecedores, produtores rurais, atacadistas e distribuidores, que a atendem periodicamente. Para que esse fornecedor seja cadastrado, ele deve apresentar um padrão mínimo exigido pela empresa. Para que a empresa compre pela primeira vez de um novo fornecedor, ele precisa, além de produtos de qualidade considerada adequada ao padrão da Empresa X, possuir no mínimo um computador com acesso à internet. O trecho a seguir, extraído de entrevistas com o comprador da Empresa $\mathrm{X}$, vai exemplificar como o mínimo exigido pela Empresa $X$ dos seus fornecedores representa um diferencial.

Com o passar dos anos a gente foi melhorando, entrou o sistema de informação com pedido e agendamento eletrônico, os produtores não entravam mais (no centro de distribuição para entregar a mercadoria) se não agendassem a nota. Então os fornecedores tiveram que se adaptar [...] eu diria que houve uma progressão muito grande no desenvolvimento dos fornecedores, eles tiveram que se modernizar, porque senão eles não iam mais conseguir entregar o produto... (Trecho extraído da entrevista com o comprador da Empresa X.)

Segundo dados fornecidos pelos entrevistados, no passado muitos dos produtores não possuíam infraestrutura necessária para a padronização dos processos, de forma que garantisse a qualidade dos produtos, e para executar procedimentos comerciais e financeiros. Entre as condições estão, por exemplo, a necessidade de um grau mínimo de informatização; o rastreamento do produto e adequação à legislação trabalhista vigente no país. Esses produtores não tinham contato com a tecnologia de informação. A Empresa $X$ capitaneou a transição para 
nova forma de organização, criando regras e fornecendo condições necessárias para que os produtores pudessem continuar na base de fornecedores ativos.

A Empresa $X$ apoiou o desenvolvimento dos então fornecedores para que eles se adaptassem às novas regras; levando treinamento e informatização até eles. Atualmente, a empresa possui uma equipe de consultores responsáveis por fazer auditorias periódicas a todos os fornecedores, para verificar se as exigências de campo estabelecidas estão sendo atendidas. Exemplos das exigências de campo são: o uso de equipamentos de proteção individual (EPIs), adequação das instalações de campo às recentes mudanças na legislação trabalhista, como oferecer área para refeição e banheiros instalados na lavoura para uso dos trabalhadores rurais. Embora para a indústria, de maneira geral, estas sejam condições estabelecidas há muitos anos, na produção rural avanços nesse sentido são recentes.

\section{O RELACIONAMENTO DO PONTO DE VISTA DO FORNECEDOR Y}

Fornecedor da Empresa X há 25 anos, o Fornecedor Y é um dos fornecedores de banana da Empresa X. Segundo os entrevistados, eles conhecem a rotina do varejista e afirmam: "...é bom vender pra eles (Empresa X) porque a quantidade e pedido são certos..."

Baseado no histórico de vendas, o fornecedor inicia o preparo da mercadoria, em geral, dois dias antes de receber o pedido. Os processos e subprocessos de colheita, embalagem e climatização, dado que o principal produto que o Fornecedor $Y$ vende para a Empresa $X$ requer climatização, são feitos com base na previsão de demanda do próprio fornecedor. Este considera a demanda de mercadoria estável.

Portanto, quando o Fornecedor $Y$ recebe o pedido da Empresa $X$, as atividades a serem feitas são apenas aquelas relacionadas ao preparo da nota de embarque, faturamento, documentos para transporte e carregamento. O pedido é recebido eletronicamente. Com o número do pedido, o fornecedor entra em contato com a área responsável pela programação das entregas no CD para fazer o agendamento da sua entrega. Embora a Empresa $X$ disponibilize o agendamento eletrônico, pela internet, o fornecedor afirma que ainda faz o agendamento por telefone.

Após o agendamento, o fornecedor prepara a documentação e envia a mercadoria para o CD. A pontualidade de entrega e a qualidade das frutas são aspectos controlados tanto pelo fornecedor quanto pela Empresa X. A entrega pontual é dever do fornecedor e o recebimento dentro da janela de tempo é dever da Empresa X. Qualquer um dos dois que não cumprir os prazos é penalizado e a parte que descumpriu a programação é multada. Multa para fornecedor que chegar atrasado e multa para a Empresa $X$ se ultrapassar o tempo de recebimento. $O$ fornecedor participante da pesquisa afirma já ter recebido multas pagas pela Empresa $X$ devido a atrasos no recebimento.

Os critérios de avaliação do fornecedor são objetivos está acessível de duas formas. A primeira, existe um ranking disponível para todos os fornecedores no ato da entrega. Ou seja, os fornecedores conseguem saber a qualidade do produto entregue por eles e a pontualidade deles em comparação aos demais fornecedores. A segunda forma de acesso é pela internet. No site da Empresa X, eles conseguem consultar o desempenho da entrega do dia e o histórico.

Os indicadores de qualidade e pontualidade fazem parte de um projeto de parceria entre o Fornecedor $Y$ e a Empresa X. A parceria consiste em participar dos projetos lançados pela Empresa $X$, que buscam integração de informação desde o produtor rural, incluindo o rastrea- 
mento dos produtos. O compromisso do fornecedor é entregar o produto dentro dos padrões de qualidade acordados, como, por exemplo, calibre e coloração. Em troca, a Empresa X compartilha com o fornecedor a programação e garante a compra. Segundo um dos entrevistados, "... nessa parceria, o vendedor não faz diferença, porque o que importa é a qualidade, você vai pra um gráfico, se você está bem no gráfico você vende, isso é a parceria...”.

O entrevistado completa:

...hoje, a gente tem acesso a essa informação, conhecemos a ficha técnica. A gente faz a avaliação e preenche a ficha técnica quando o produto sai daqui, que é mesma ficha que eles vão ter lá. Vamos começar a confrontar o resultado nosso com o deles. Sabemos que se tiver diferença, a gente pode levar essa informação para eles. Hoje em dia, tem essa chance...

O fornecedor destacou também a possibilidade de desenvolverem atividades em conjunto para melhorar a venda do produto e reduzir os índices de perda no ambiente de loja. No relato, o entrevistado descreve duas experiências. A primeira foi feita há cinco anos em duas lojas da Empresa X. Foi um projeto-piloto para a entrada direta na loja (EDL), ou seja, ao invés de levar toda a mercadoria para o $\mathrm{CD}$, o fornecedor entregava a mercadoria direto na loja. Embora os resultados fossem positivos, esse projeto com as lojas ficou apenas no piloto.

A segunda foi o desenvolvimento por parte do fornecedor de dispositivos para a exposição do produto. Esse dispositivo foi adotado em parte das lojas da Empresa X. As demais lojas não adotaram o dispositivo para a exposição do produto e continuam a expor o produto nas bancas. O fornecedor afirma que os índices de perda são menores com o uso do dispositivo para exposição, e por isso não entende por que a Empresa $X$ adotou o dispositivo em apenas parte das lojas.

O preço é determinado pelo mercado, conforme ilustrado no trecho da entrevista: ".... gente sempre discute preço, mas como a gente entrega volume, tem que ganhar nisso. Outras redes falam que nossa fruta é mais cara, mas não é só mais cara, eu mostro para ele que ele vai vender mais e vai perder menos. Mas muitos têm a cabeça de preço..."

\section{DISCUSSÃO}

Ao se comparar os resultados obtidos do estudo de caso com os requisitos levantados no referencial teórico, pode-se identificar alguns fatores que inibem a adoção de práticas de gestão colaborativa, especificamente VMI, CRP, ECR e CPFR, no elo fornecedor-varejo supermercadista na cadeia de suprimento de frutas e legumes.

Com base nos dados coletados, pode-se dizer que a Empresa $X$ tem desenvolvido relacionamentos colaborativos com os seus fornecedores. $O$ relacionamento de parceria entre a Empresa $X$ e o Fornecedor $Y$ pode ser observado tanto nos relatos dos funcionários da empresa quanto nos relatos do fornecedor, os quais são caracterizados pela troca de informações e pela visibilidade dos processos ao longo da cadeia.

No entanto, o comportamento colaborativo é um requisito necessário, mas não o suficiente para que sejam implementadas as práticas de gestão VMI, CRP, ECR, e CPFR. É necessária também a integração de informações e compatibilidade tecnológica. Embora haja troca de informações, não foi possível observar a integração de informações. As empresas 
envolvidas na parceria trocam informações, de forma que o varejista pode consultar informações do fornecedor e vice-versa. Mas a integração no sentido de compartilhamento intensivo de informações não foi observada.

No que diz respeito à compatibilidade tecnológica, observou-se, segundo relato sobre a base de fornecedores, uma incompatibilidade. Assim, conforme relatado pelo comprador, em termos gerais, a base de fornecedores possui limitações relacionadas ao uso de sistemas de informação. O Quadro 5 apresenta um comparativo entre os requisitos para a implementação das práticas de gestão colaborativa VMI, ECR, CRP e CPFR e o praticado pela Empresa X e pelo Fornecedor $Y$.

Observa-se que, dos onze requisitos identificados para a adoção das práticas de gestão colaborativa, o elo fornecedor-varejo supermercadista na cadeia de suprimento de frutas e legumes atende a apenas seis deles. Isso evidencia uma lacuna entre o que é necessário e o que é praticado pelas empresas, indicando assim um conjunto de fatores que inibem a implementação das práticas de gestão colaborativa VMI, ECR, CRP e CPFR.

De acordo com o exposto no Quadro 5, pode-se sugerir que os fatores que inibem a adoção das práticas de gestão colaborativa VMI, ECR, CRP e CPFR no elo fornecedor-varejo supermercadista na cadeia de suprimento de frutas e legumes são predominantemente relacionados à (i) dificuldade de se estabelecer extensiva troca/compartilhamento de informação com os membros da cadeia de suprimentos; (ii) falta de integração de informações, o não uso ou o uso limitado de sistemas em comum e a falta de compatibilidade tecnológica; (iii) ausência de objetivos mútuos; (iv) ausência de tomada de decisão conjunta; e (v) falta do uso intensivo de tecnologias de informação e integração de sistemas. Aspectos relacionados à segurança de sistemas nem chegaram a ser mencionados.

Ao se identificar os fatores já mencionados como fatores que inibem a adoção das práticas de gestão colaborativa VMI, ECR, CRP e CPFR, alcança-se o objetivo proposto neste artigo. Em síntese, pode-se observar o estabelecimento de parcerias, mas sem a implementação das práticas de gestão referidas, as quais têm como base o relacionamento colaborativo. Esse resultado é interessante à medida que abre um precedente para se afirmar que é possível avançar nos relacionamentos colaborativos, e alcançar benefícios desses relacionamentos mesmo sem a implementação das práticas de gestão VMI, CRP; ECR e CPFR.

\section{CONSIDERAÇÕES FINAIS}

Com base nos dados coletados, pode-se concluir que a Empresa X procura desenvolver relacionamentos colaborativos com os seus fornecedores de frutas e legumes. Embora na Empresa $X$, o uso de sistemas de informação seja uma prática estabelecida, o uso de tais sistemas por parte dos fornecedores ainda é limitado. Ou seja, a base de fornecedores da Empresa $X$ não está capacitada em termos de tecnologia da informação para a implementação das práticas colaborativas VMI, CRP; ECR e CPFR.

Entende-se que a colaboração entre empresas pode implicar em melhor visibilidade dentro da cadeia. Uma melhor visibilidade permite que as empresas organizem seus processos com possibilidade de reduzir lead times e, por conseguinte, aumentar o tempo útil da vida de prateleira dos produtos, tempo esse que pode ser dedicado à exposição em gôndola reduzindo os índices de perda. 
Quadro 5: Análise dos requisitos para a implementação de práticas de gestão colaborativa VMI, ECR, CRP e CPFR na Empresa X.

\begin{tabular}{|c|c|c|}
\hline $\begin{array}{l}\text { Requisitos para } \\
\text { implementação }\end{array}$ & Empresa $\mathrm{X}$ & Fornecedor Y \\
\hline $\begin{array}{l}\text { Comunicação entre } \\
\text { departamentos }\end{array}$ & \multicolumn{2}{|c|}{$\begin{array}{c}\text { Pode-se observar integração entre os departamentos da Empresa } X \text { e do } \\
\text { Fornecedor } Y\end{array}$} \\
\hline $\begin{array}{l}\text { Capacidade da organização } \\
\text { em inovar e provocar } \\
\text { mudanças administrativas }\end{array}$ & \multicolumn{2}{|c|}{$\begin{array}{l}\text { Tanto o fornecedor analisado, quanto a Empresa } X \text { mostraram-se capazes de } \\
\text { promover mudanças administrativas }\end{array}$} \\
\hline Apoio da alta administração & \multicolumn{2}{|c|}{$\begin{array}{l}\text { Os relacionamentos colaborativos observados indicam haver o apoio da alta } \\
\text { administração tanto no fornecedor analisado, quanto na Empresa } X\end{array}$} \\
\hline $\begin{array}{l}\text { Relacionamento de parceria } \\
\text { baseado na confiança }\end{array}$ & \multicolumn{2}{|c|}{$\begin{array}{c}\text { Os relacionamentos colaborativos apontam na direção da construção de } \\
\text { relacionamento de confiança }\end{array}$} \\
\hline $\begin{array}{l}\text { Coordenação de processos e } \\
\text { operações entre as empresas } \\
\text { da cadeia de suprimentos }\end{array}$ & \multicolumn{2}{|c|}{$\begin{array}{l}\text { A possibilidade de visibilidade e os relacionamentos colaborativos apontam } \\
\text { para a coordenação de processos entre as empresas analisadas }\end{array}$} \\
\hline $\begin{array}{l}\text { Objetivos } \\
\text { compartilhados/mútuos }\end{array}$ & \multicolumn{2}{|c|}{ O que existe são objetivos de desempenho no elo, não objetivos compartilhados } \\
\hline Tomada de decisão conjunta & \multicolumn{2}{|c|}{$\begin{array}{c}\text { Embora haja parceria entre a Empresa } X \text { e o Fornecedor } Y \text {, não se pode afirmar } \\
\text { que haja tomada de decisão conjunta }\end{array}$} \\
\hline Compatibilidade cultural & \multicolumn{2}{|c|}{ As organizações mostraram-se alinhadas culturalmente } \\
\hline $\begin{array}{l}\text { Extensiva } \\
\text { troca/compartilhamento de } \\
\text { informação com os } \\
\text { membros da cadeia de } \\
\text { suprimentos }\end{array}$ & $\begin{array}{l}\text { Existe troca de informação, no } \\
\text { entanto não pode-se afirmar que seja } \\
\text { extensiva }\end{array}$ & $\begin{array}{l}\text { O Fornecedor Y compartilha } \\
\text { principalmente informações técnicas } \\
\text { referente aos processos e qualidade do } \\
\text { produto. Dados de previsão de } \\
\text { demanda, por exemplo, não são } \\
\text { compartilhados no curto prazo. }\end{array}$ \\
\hline $\begin{array}{l}\text { Integração de } \\
\text { informações/uso de sistemas } \\
\text { em comum/compatibilidade } \\
\text { tecnológica }\end{array}$ & $\begin{array}{l}\text { A Empresa X está tecnicamente } \\
\text { capacitada para a integração de } \\
\text { informações e uso de sistemas em } \\
\text { comum }\end{array}$ & $\begin{array}{l}\text { Mesmo o Fornecedor } Y \text { sendo } \\
\text { considerado pela Empresa } X \text { um } \\
\text { parceiro em atividades inovadoras, } \\
\text { existe neste requisito uma maior } \\
\text { dificuldade da parte do fornecedor. Isso } \\
\text { pode ser ilustrado pelo fato dele fazer o } \\
\text { agendamento por telefone, quando } \\
\text { poderia usar um sistema comum às } \\
\text { duas empresas. Consiste, portanto, em } \\
\text { um dos fatores inibidores à } \\
\text { implementação das práticas, } \\
\text { especialmente no que tange à } \\
\text { compatibilidade tecnológica da base de } \\
\text { fornecedores }\end{array}$ \\
\hline $\begin{array}{l}\text { Uso intensivo de tecnologias } \\
\text { de informação e integração } \\
\text { de sistemas/ segurança de } \\
\text { sistemas }\end{array}$ & $\begin{array}{l}\text { A Empresa } X \text { dispõe das tecnologias } \\
\text { e sistemas de informação necessários } \\
\text { para a implementação. }\end{array}$ & $\begin{array}{l}\text { há incompatibilidade tecnológica dos } \\
\text { fornecedores para que haja integração } \\
\text { de sistemas, de forma que inviabiliza a } \\
\text { implementação das práticas VMI, } \\
\text { ECR, CRP e CPFR }\end{array}$ \\
\hline
\end{tabular}

Fonte: Elaborado pelas autoras

Ao desenvolver um relacionamento próximo aos fornecedores, a organização, possivelmente, terá chances de reduzir os riscos relacionados à não entrega de produtos e/ou prestação de serviços, ou ainda, riscos dos produtos e/ou serviços solicitados não estarem em conformidade com o que foi pedido. Assim, esse tipo de comportamento acaba influenciando de maneira positiva a confiabilidade de entrega, bem como a qualidade do produto. 
O conhecimento do fato que as empresas da cadeia de suprimentos de frutas e legumes não estão aptas a implementar as práticas do VMI, CRP, ECR e CPFR, pode indicar que são necessários o desenvolvimento de práticas menos sofisticadas que possam ser implementadas nesse contexto.

A pesquisa realizada coleta dados do ponto de vista do fornecedor, no entanto, foi incluído no estudo de caso apenas um fornecedor, o que não permite uma análise completamente isenta das opiniões dos entrevistados. Seria necessário um estudo que abrangesse um número maior de fornecedores.

Outra limitação deste estudo é a dificuldade de generalização dos resultados obtidos para outras categorias de produtos, ou mesmo, a comparação dos resultados obtidos na pesquisa no setor de hortifrúti com outras categorias de produto dentro das empresas pesquisadas. A coleta de dados nas mesmas áreas da Empresa $X$ responsáveis pelos itens de mercearia seca e a inclusão de fornecedores desses itens poderia indicar requisitos não identificados na literatura. Essa comparação entre os fornecedores de diferentes categorias de produtos, em particular itens industrializados e frutas e legumes, pode contribuir também para uma melhor compreensão dos fatores que inibem a adoção de práticas de gestão utilizadas com um grupo de fornecedores, mas não com o outro.

Por fim, para trabalhos futuros, sugere-se: identificar os efeitos da adoção de práticas colaborativas entre empresas supermercadistas e seus fornecedores de hortifrúti; avaliar se o comportamento colaborativo resulta em melhoria na disponibilidade do produto; e desenvolver esse mesmo estudo considerando outras categorias de produto. A realização de estudos que envolvam mais de uma categoria de produto viabilizaria a comparação das mesmas, de forma a verificar a influência da base de fornecedores na gestão colaborativa.

\section{REFERÊNCIAS}

AASTRUP, J.; KOTZAB, H. Analyzing out-of-stock in independent grocery stores: an empirical study. International Journal of Retail \& Distribution Management, v. 37, n. 9, p. 765-789, 2009.

AASTRUP, J.; KOTZAB, H. Forty years of out-of-stock research - and the shelves are still empty. The International Review of Retail, Distribution and Consumer Research, v. 20, n. 1, p. 147-164, 2010.

BARRAT'T, M. Positioning the role of collaborative planning in grocery supply chains. International Journal of Logistics Management, v. 14, n. 2, p. 53-66, 2003.

BARRATT, M. Understanding the meaning of collaboration in the supply chain. Supply Chain Management: an International Journal, v. 9, n. 1, p. 30-42, 2004.

CADILHON, J. J.; FEARNE, A. P.; TAM, P. T. G.; MOUSTIER, P.; POOLE, N. D. Collaborative commerce or just common sense? Insights from vegetable supply chains in Ho Chi Minh City. Supply Chain Management: An International Journal, v. 10, n. 3, p. 147-149, 2005.

DAUGHTERTY, P. J.; MYERS, M. B.; AUTRY, C. D. Automatic replenishment programs: an empirical examination. Journal of Business Logistics, v. 20, n. 2, p. 63-82, 1999.

DONG, Y.; XU, K.; DRESNER, M. Environmental determinants of VMI adoption: an exploratory analysis. Transportation Research Part E: Logistics and Transportation Re- 
view, v. 43, n. 4, p. 355-369, 2007.

EISENHARDT, K. M. Building theories from case study research. Academy of Management Review, v. 14, n. 4, p. 532-550, 1989.

ELLRAM, L. M. The use of case study method in logistics research. Journal of Business Logistics, v. 17, n. 2, p. 93-138, 1996.

FAWCETT, S. E.; MAGNAN, G. M.; FAWCETT, A. M. Mitigating resisting forces to achieve the collaboration-enabled supply chain. Benchmarking: An International Journal, v. 17, n. 2, p. 269-293, 2010.

FAWCETT, S. E.; MAGNAN, G. M.; McCARTER, M. W. Benefits, barriers, and bridges to effective supply chain management. Supply Chain Management: An International Journal, v. 13 , n. 1, p. 35-48, 2008.

FU, H.; CHU, K.; LIN, S.; CHEN, C. A study on factors for retailers implementing CPFR - a fuzzy AHP analysis. Journal of Systems Science and Systems Engineering, v. 19, n. 2, p. 192-209, 2010.

GRANT, D. B.; FERNIE, J. Research note: Exploring out-of-stock and on-shelf availability in non-grocery, high street retailing. International Journal of Retail \& Distribution Management, v. 36, n. 8, p. 661-672, 2008.

HOLMSTRÖM, J.; FRÄMLING, K.; KAIPIA, R.; SARANEN, J. Collaborative planning forecasting and replenishment: new solutions needed for mass collaboration. Supply Chain Management: an International Journal, v. 7, n. 2, p. 136-145, 2002.

IRELAND, R.; BRUCE, R. CPFR - only the beginning of collaboration. Supply Chain Management Review, v. 4, n. 4, p. 80-88, 2000.

KURNIA, S; JOHNSTON, R. B. Adoption of efficient consumer response: the issue of mutuality. Supply Chain Management: an International Journal, v. 6, n. 5, p. 230-241, 2001.

KURNIA, S; JOHNSTON, R. B. The need for a processual view of inter-organizational systems adoption. Journal of Strategic Information Systems, v. 9, n. 4, p. 295-319, 2000.

LOURENZANI, A. E. B. S.; SILVA, A. L. Um estudo da competitividade dos diferentes canais de distribuição de hortaliças. Gestão \& Produção, v. 11, n. 3, p. 385-398, 2004.

MÖLLER, K.; SVAHN, S. Crossing East-West boundaries: Knowledge sharing in intercultural business networks. Industrial Marketing Management, 33, p. 219-228, 2004.

PELIÇÃO, T. Z.; NEVES, M. F.; MARTINELLI, D. P. Gestão de compra de produtos hortícolas por varejistas: análise de estratégias empresariais. Gestão \& Produção, v. 6, n. 3, p. 233-242, 1999.

PELLEGRINOTTTI, C. C. Gestão colaborativa: um estudo no setor automobilístico brasileiro, 2011, 90p. Dissertação de Mestrado. Universidade de São Paulo, São Carlos, 2011.

PIGAT'TO, G.; ALCANTARA, R. L. C. Relacionamento colaborativo no canal de distribuição: uma matriz para análise. Gestão \& Produção, v. 14, n. 1, p. 167-177, 2007. 
PIRES, S. R. I. Gestão da Cadeia de Suprimentos (Supply Chain Management): conceitos, estratégias, práticas e casos, São Paulo: Editora Atlas S.A., 2004, 310 p.

PRAMATARI, K. Collaborative supply chain practices and evolving technological approaches. Supply Chain Management: An International Journal, v. 12, n. 3, p. 210-220, 2007.

RANKING ABRAS. Mais um ano dourado - setor superou os R $\$ 200$ bilhões em 2010. Revista SuperHiper, n. 418, p. 40-140, abr., 2011.

SABATH, R. E.; AUTRY, C. W.; DAUGHERTY, P. J. Automatic replenishment programs: the impact of organizational structure. Journal of Business Logistics, v. 22, n. 1, p. 91-105, 2001.

SHEU, C.; YEN, H. R.; CHAE, B. Determinants of supplier-retailer collaboration: evidence from an international study. International Journal of Operations \& Production Management, v. 26, n. 1, p. 24-49, 2006.

SIMATUPANG, T. M.; SRIDHARAN, R. The collaborative supply chain. International Journal of Logistics Management, v. 13, n. 1, p. 15-30, 2002.

SIMUTAPANG, T. M.; WRIGHT, A. C.; SRIDHARAN, R. Applying the theory of constraints to supply chain collaboration. Supply Chain Management: An International Journal, v. 9, n. 1, p. 57-70, 2004.

TURBAN, E.; RAINER JR., R. K.; POTTER, R. E. Introdução à sistemas de informação, 2. reimpressão, Rio de Janeiro: Elsevier, 2007.

VIEIRA, J. G. V.; YOSHIZAKI, H. T. Y.; HO, L. Collaboration intensity in the Brazilian supermarket retail chain. Supply Chain Management: An International Journal, v. 14, n. 1, p. 11-21, 2009.

VIVALDINI, M.; PIRES, S. R. I. Operadores Logísticos: integrando operações em cadeias de suprimentos, São Paulo: Atlas, 2010, 214 p.

WHIPPLE, J. M.; RUSSELL, D. Building supply chain collaboration: a typology of collaborative approaches. International Journal of Logistics Management, v. 18, n. 2, p. 174-196, 2007.

YIN, R. K. Estudo de caso - planejamento e métodos, 2. ed., Porto Alegre: Bookman, 2005.

Submetido em: 6-9-2016

Aceito em: 30-11-2016 